\title{
Predictive and prognostic value of Matrix metalloproteinase (MMP) - 9 in neoadjuvant chemotherapy for triple- negative breast cancer patients
}

\author{
Ruo-Xi Wang ${ }^{1,2}$, Sheng Chen ${ }^{1,2^{*}}$ (D), Liang Huang ${ }^{1,2}$ and Zhi-Ming Shao ${ }^{1,2,3^{*}}$
}

\begin{abstract}
Background: This study aimed to investigate the clinical utility of serum and histological MMP-9 detection during neoadjuvant chemotherapy (NAC) for triple-negative breast cancer (TNBC).

Methods: A total of 303 TNBC patients who underwent weekly paclitaxel plus carboplatin treatments followed by surgical resection were included in this study. Enzyme-linked immunosorbent assay (ELISA) was used to detect the serum level of Matrix metalloproteinase-9 (sMMP-9) at baseline and prior to surgery. Immunohistochemistry was used to detect histological MMP-9 (hMMP-9) expression in patients with residual tumors after NAC. The value of MMP-9 to predict the response to NAC and patient survival was studied.

Results: Of the 303 patients, 103 (34.0\%) patients experienced pathological complete response (pCR) after completion of NAC. Univariate and multivariate analyses revealed that the relative change in SMMP-9, rather than SMMP-9 at baseline or surgery, had a remarkable predictive value for $\mathrm{pCR}$. Each $1 \mathrm{ng} / \mathrm{ml}$ decrease in SMMP-9 after NAC was shown to result in a $0.3 \%$ increase in pCR rate. Additionally, in survival analyses, hMMP-9 expression in residual tumors was independently correlated with disease-free survival for non-pCR responders $(P<0.001)$.

Conclusions: Our findings indicate that monitoring serum MMP-9 and detection of histological MMP-9 could help identify TNBC patients who will respond to NAC and will display varying risks of disease relapse. MMP-9 may serve as a predictive and prognostic biomarker for tailoring and modifying the NAC strategy for TNBC.
\end{abstract}

Keywords: Breast cancer, Neoadjuvant chemotherapy, MMP-9, Pathological response, Prognostic marker

\section{Background}

Triple-negative breast cancer (TNBC) is a type of breast cancer that lacks the expression of estrogen receptor (ER), progesterone receptor (PgR) and human epidermal growth factor receptor-2 (HER2). It comprises 15-20\% of all breast cancers and has an aggressive tumor biology [1]. For locally advanced TNBC, neoadjuvant chemotherapy (NAC) followed by definitive surgery is a standard of care. It is also an option for early-stage TNBC to increase the chance of breast-conserving surgery. The

\footnotetext{
* Correspondence: 0456177@fudan.edu.cn; zhimingshao001@163.com 'Department of Breast Surgery, Fudan University Shanghai Cancer Center/ Cancer Institute, 399 Ling-Ling Road, Shanghai 200032, People's Republic of China

Full list of author information is available at the end of the article
}

use of NAC has also provided insight into tumor biology and differential responses to treatment. The result of NAC, often evaluated by pathological response according to surgical specimens, has significantly impacted patient survival. The patients who have achieved pathological complete response (pCR) have a relatively lower risk of disease relapse or death compared to those who have residual disease after NAC $[2,3]$.

In a neoadjuvant setting, although TNBCs have a higher $\mathrm{pCR}$ rate compared with other subtypes [4], it is not clearly translated into an improved overall survival [5]. This is possibly due to a poor outcome of non-pCR responders. Since TNBC has proved to be a heterogeneous disease comprising subtypes with different biological behaviors and clinical outcomes [6,7], strategies

(c) The Author(s). 2018 Open Access This article is distributed under the terms of the Creative Commons Attribution 4.0 International License (http://creativecommons.org/licenses/by/4.0/), which permits unrestricted use, distribution, and 
that identify candidates who respond differently or display a better prognosis as a result of NAC are needed. Several pathological biomarkers have been investigated including P53, cytokeratin (CK) 5/6, CK14, epidermal growth factor receptor (EGFR), and Ki-67 [6, 7]. However, clinically applicable biologic markers of predictive or prognostic value are still limited.

Matrix metalloproteinases (MMPs) are a family of zinc-dependent endopeptidases that are involved in the degradation of the extracellular matrix (ECM) [8]. Several MMPs share a large amount of common structural and functional similarities and have been found to play key roles in cancer invasion and metastasis, angiogenesis and tumorigenesis [9-11]. Recently, a meta-analysis comprising 28 studies indicated that MMP-9 expression in serum and tumor tissue acts as a predictor for worse prognosis in breast cancer [12]. However, few attempts have been made to investigate the predictive and prognostic value of MMP-9 on TNBCs specifically. This study was designed to demonstrate the practical utility of MMP-9 detection in a neoadjuvant setting and to establish a new strategy to identify subgroups of TNBC patients with different risk.

\section{Methods}

\section{Study population}

In this study, we selected 303 patients with TNBC according to inclusive and exclusive criteria reported previously [13]. The cut-off values of $1 \%$ of positive tumor cells were used for ER positivity and PgR positivity. Circumferential membrane-bound staining of $0,1+, 2+$ or $3+$ were used to evaluated HER2 expression. Positivity for HER2 (HER2+) was considered as $3+$ using IHC or as positive on fluorescence in situ hybridization (FISH). Only tumors with negative expression of ER, PgR and HER2 were considered as TNBC. All patients were confirmed with invasive breast cancer by core needle biopsy. The regimen of NAC was weekly PC (paclitaxel plus carboplatin) followed by surgical resection at Fudan University Shanghai Cancer Center between January 2009 and July 2015. Our study was approved by the independent ethical committee/institutional review board of our center (Shanghai Cancer Center Ethical Committee). All patients gave their written informed consent before inclusion in this study.

The NAC regimen was paclitaxel $\left(80 \mathrm{mg} / \mathrm{m}^{2}\right)$ and carboplatin (AUC $2 \mathrm{mg} * \mathrm{~min} / \mathrm{ml}$ ) on days 1,8 , and 15 of a 28-day cycle for 6 cycles. Following NAC, all patients received mastectomy or breast conserving surgery to remove the primary tumor, and axillary lymph nodes dissection to remove lymph nodes. After pathological evaluation of surgical specimens, patients with complete response (pCR) would receive two additional cycles of $\mathrm{PC}$, whereas non-pCR responders would receive three cycles of anthracycline-based chemotherapy. The performing of radiation therapy was at the discretion of the treating radiologist.

\section{Response evaluation}

Response Evaluation Criteria in Solid Tumors (RECIST) version 1.1 [14] was used in evaluation of clinical response based on MRI and ultrasound examinations. Miller-Payne (MP) grading system [15] was used to evaluate pathological response. Pathological complete response was defined as no residual invasive cancer in either the breast or lymph nodes.

\section{ELISA and immunohistochemistry}

Serum samples were obtained prior to the start of NAC and prior to surgery. Patients' blood was drawn using standard protocols and was collected in the absence of anticoagulant. Sera were then separated through centrifugation. All sera sample were stored at $-80{ }^{\circ} \mathrm{C}$. No more than two freeze-thaw cycles were allowed before the procedure of enzyme-linked immunosorbent assay (ELISA). The MMP-9 level in each sample was then measured with antibody from Proteintech (10375-2-AP, Rosemont, IL, USA). Measurement of MMP-9 was marked as the average level of the repeated results (three times). The mean standard error was 0.511. Expression of MMP-9 protein in the tissue sections from surgical specimens after NAC were evaluated through Immunohistochemistry (IHC) with antibody from Cell Signaling Technology (\#13667, Danvers, MA, USA). Sections of spleen tissue were used as a positive control. Two pathologists reviewed and measured the results of IHC independently using the $\mathrm{H}$ score. The intensity of positivity was scored as no staining (0), weak staining $(+1)$, moderate staining $(+2)$ and intense staining $(+3)$. In this study, we defined patients with an $\mathrm{H}$ score of $0-100$ as MMP-9 negative (-), 100-200 as moderately positive $(+)$ and $200-300$ as strongly positive (++) (Fig. 1).

\section{Statistical analysis}

Two-tailed Student's T test was used to compare means between two groups (in Fig. 2 and Fig. 3). Relationship between patient characteristics and response were evaluated by Chi-squared test. Logistic regression model with the forward selection of variables was used to identify the independent predictors of treatment response. DFS was calculated from the date of surgery to disease relapse (local or distant relapse or death from any cause). Patients without events or death were censored at the last follow-up. Cox regression model was used to investigate the prognostic variables. Kaplan-Meier survival curves, together with the log-rank test was performed to show the difference between risk groups. All statistical tests were two-sided, and $P$ values less than 0.05 were considered significant. 




Fig. 1 Immunohistochemical staining of MMP-9 in post-NAC samples of breast cancer. MMP-9 protein was detected with immunohistochemistry (IHC) using paraffin-embedded breast cancer samples collected after neoadjuvant chemotherapy. a Representative IHC images of strongly positive MMP-9 staining (200X). b Representative IHC images of moderate MMP-9 staining. c Representative $\mathrm{HC}$ images of negative MMP-9 staining (200X). Scale bar: $50 \mu \mathrm{m}$

SPSS (version 19.0, SPSS Company, Chicago, IL, USA) software was used to perform the Statistical analyses.

\section{Results}

Patient characteristics

Patient characteristics are shown in Table 1. Among 303 patients in this study, the median age was 50 years

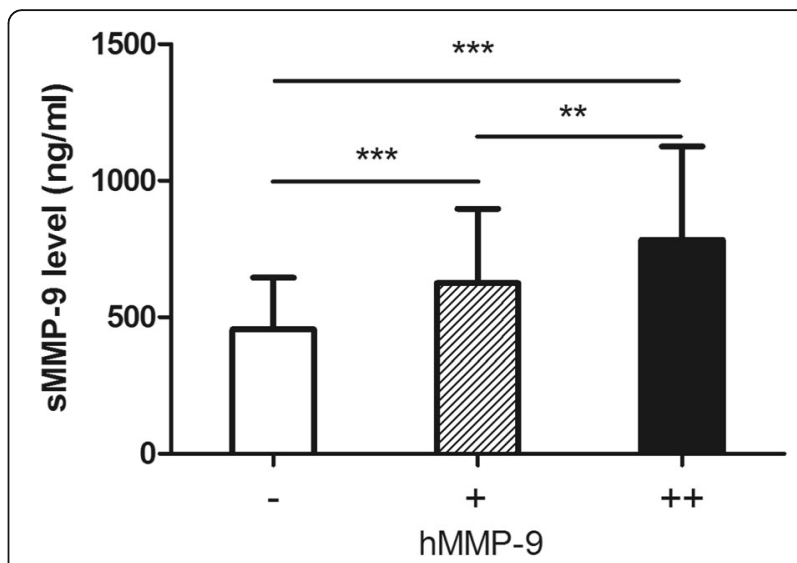

Fig. 2 Correlation between serum and histological MMP-9 in non-pCR patients. A higher serum MMP-9 (sMMP-9) level is more frequently observed in patients with higher positivity of histological MMP-9 level (hMMP-9), ${ }^{* * *} P<0.001$, ${ }^{* *} P<0.01$

(range, 27-74 years). A total of $52.5 \%$ of patients were pre-menopausal at diagnosis. All patients were diagnosed with stage II or III disease, and $82.8 \%$ of them had positive lymph nodes prior to NAC. Ki-67 expression of biopsy specimens was also evaluated, and $64.7 \%$ of patients had a Ki-67 level greater than $20 \%$.

\section{MMP-9 expression}

Serum MMP-9 (sMMP-9) was measured by ELISA at two time points: prior to the start of NAC (at baseline), and prior to surgery (at surgery). The median levels of sMMP-9 at baseline and surgery were $607.2 \mathrm{ng} / \mathrm{ml}$ (range: $241.2 \mathrm{ng} / \mathrm{ml} \mathrm{-} 1172.4 \mathrm{ng} / \mathrm{ml}$ ) and $513.5 \mathrm{ng} / \mathrm{ml}$ (range: $120.4 \mathrm{ng} / \mathrm{ml}$ - $1886.7 \mathrm{ng} / \mathrm{ml}$ ), respectively. The change in sMMP-9 level was calculated, and the median reduction was $82.2 \mathrm{ng} / \mathrm{ml}$ (range: - 878.3 - 629.5).

Histological MMP-9 (hMMP-9) was measured by IHC on surgical specimens of residual tumors. hMMP-9 data were available for 200 patients with residual tumors after NAC (non-pCR responders). According to the H-score, 81 patients $(40.5 \%)$ were considered as hMMP-9 negative $(-)$, whereas 55 patients $(27.5 \%)$ were considered as weakly or moderately positive $(+)$. Sixty-four patient samples $(32.0 \%)$ were considered to be strongly positive $(++)$ for hMMP-9. We also studied the correlation between sMMP-9 and hMMP-9. Higher sMMP-9 level (at surgery) is more frequently observed in patients with a higher positivity of hMMP-9, indicating a concordance between serum and histological expression (Fig. 2).

\section{sMMP-9 and treatment response}

Of the 303 patients, 103 (34.0\%) experienced pCR after completion of NAC. Table 1 shows the results of the Chi-squared test and multivariate logistic regression analysis for pCR predictors. Correlations between $\mathrm{pCR}$ and 


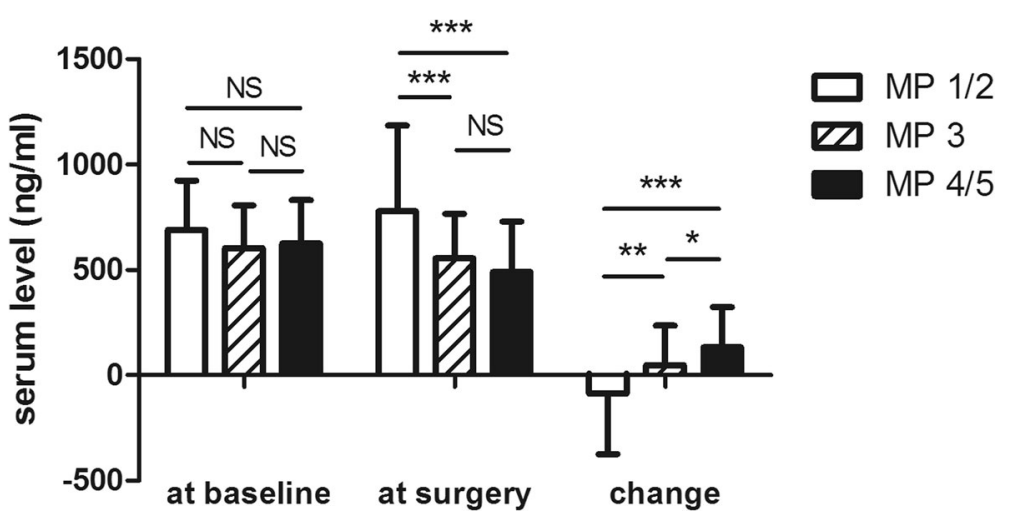

Fig. 3 Correlation between serum MMP-9 value and Miller-Payne (MP) grades. MMP-9 change after NAC was significantly correlated to response to NAC. The mean absolute changes $(\mathrm{ng} / \mathrm{ml})$ in serum MMP-9 were $-88.30 \pm 286.40,47.70 \pm 188.60$ and $133.00 \pm 190.40$ in patients with a poor response (MP 2/1), a partial response (MP 3) and an ideal response (MP 5/4), respectively. ${ }^{* *} P<0.001,{ }^{* *} P<0.01,{ }^{*} P<0.05$

clinical or pathological variables, including patient age, menopausal status, primary tumor size, node status, stage, Ki-67 value, sMMP-9 and clinical response, were determined. The sMMP-9 category was defined according to the tertile cutoff points. A lower level of sMMP-9 at surgery and a higher level of sMMP-9 decrease were correlated with a higher possibility of achieving pCR; however, sMMP-9 at baseline was not a predictor of pCR $(P=0.519)$. In multivariate analysis, the decrease in sMMP-9 independently correlated with $\mathrm{pCR}$ as a continuous variable $(P=0.003, \mathrm{HR}=1.003$, 95\% CI: $1.002-$ 1.005). Each $1 \mathrm{ng} / \mathrm{ml}$ decrease in the sMMP-9 level after NAC resulted in a $0.3 \%$ increase in the pCR rate. SMMP-9 at surgery also tended to be correlated with pCR $\quad(P=0.046, \quad \mathrm{HR}=0.997, \quad 95 \% \mathrm{CI}: \quad 0.994-0.998)$. Tumor size and Ki-67 expression at baseline were also independent predictors of $\mathrm{pCR}(P=0.030, \mathrm{HR}=0.536$ for T3, and $\mathrm{HR}=0.430$ for T4, T2 as reference; and $P=$ $0.001, \mathrm{HR}=2.826$ for high Ki67, low Ki-67 as reference, respectively).

The correlation between the sMMP-9 level and tumor regression (according to MP grades) is shown in Fig. 3. A significant decrease in sMMP-9 after NAC was most frequently observed in patients with a relatively better response. The mean absolute decrease in the sMMP-9 value was $133.0 \mathrm{ng} / \mathrm{ml}$ in patients with an ideal response (MP 5/4), $47.7 \mathrm{ng} / \mathrm{ml}$ in patients with a partial response (MP 3), and $-88.3 \mathrm{ng} / \mathrm{ml}$ in patients with a poor response (MP 2/1).

\section{MMP-9 and patient survival}

The median follow-up time for all patients was 45 months. Among the 103 pCR patients, only 4 developed disease recurrence or metastasis. However, non-pCR responders had a relatively poor survival, with $65(32.5 \%)$ cases of event or death.
Among the 200 non-pCR responders, univariate survival analysis was performed to assess the prognostic value of each variable. Residual tumor size $(P<0.001)$, residual node involvement $(P<0.001)$, vascular invasion $(P=0.035)$, residual tumor Ki-67 $(P=0.001)$, sMMP-9 at surgery $(P=0.008)$, sMMP-9 change $(P=0.019)$ and hMMP-9 $(P<0.001)$ were significant predictors of DFS and were entered into the multivariate Cox regression model with forward selection. Patient age, menopausal status, primary tumor size, primary node status, primary Ki-67 expression, residual tumor grade and sMMP-9 at baseline were not significant variables. In the Cox model (Table 2), hMMP-9 expression was an independent prognostic value of DFS (hMPP-9+, HR $=2.637,95 \% \mathrm{CI}$ : 1.341-5.183; hMMP-9++, HR $=2.832$, 95\% CI: $1.348-$ 5.950, hMMP-9- was used as a reference; $P=0.004)$. Residual node involvement $(P<0.001)$ and $\mathrm{Ki}-67$ value $(P=0.018)$ were also independent predictors of patient outcome. Better survival was more frequently observed in patients with a lower expression of hMMP-9, a lower Ki-67 value and fewer involved nodes. The distributions of survival curves by categorical MMP-9 are shown in Fig. 4. Compared to sMMP-9, hMMP-9 expression can better identify patients with different risk of relapse or death (Log-rank test $P<0.001)$. The observed 3-year RFS for hMMP-9 -, +, and ++ was $88.2 \%( \pm 3.8 \%), 65.1 \%$ $( \pm 7.2 \%)$, and $49.8 \%( \pm 6.4 \%)$, respectively.

\section{Discussion}

pCR following NAC implies the absence of residual invasive disease and strongly correlates with prolonged patient survival $[2,3]$. Compared with other breast cancer subtypes, TNBC has a relatively higher possibility of achieving pCR; however, this advantage is not clearly translated into an improved overall survival due to the poor outcomes of non-pCR responders [5]. Therefore, the early identification of sensitive responders would 
Table 1 Patient characteristics and observed pathological complete response (pCR)

\begin{tabular}{|c|c|c|c|c|c|c|c|c|c|}
\hline Characteristics & $\begin{array}{l}\text { Number of } \\
\text { patients }\end{array}$ & $\begin{array}{l}\text { Number of } \\
\text { pCR (\%) }\end{array}$ & $\begin{array}{l}\text { Chi-squared } \\
\text { test } P \text { value }\end{array}$ & $\begin{array}{l}\text { Multivariate } \\
P \text { value }\end{array}$ & Characteristics & $\begin{array}{l}\text { Number of } \\
\text { patients }\end{array}$ & $\begin{array}{l}\text { Number of } \\
\text { pCR (\%) }\end{array}$ & $\begin{array}{l}\text { Chi-squared } \\
\text { test } P \text { value }\end{array}$ & $\begin{array}{l}\text { Multivariate } \\
P \text { value }\end{array}$ \\
\hline Age & & & 0.564 & NS & Clinical response & & & 0.172 & NS \\
\hline$<40$ & 60 & $23(38.3)$ & & & CR/PR & 102 & $40(39.2)$ & & \\
\hline $40-59$ & 194 & $66(34.0)$ & & & $\mathrm{SD} / \mathrm{PD}$ & 201 & $63(31.3)$ & & \\
\hline
\end{tabular}

Menopausal status

$0.817 \quad N S$

$\begin{array}{lll}\text { Pre } & 159 & 55(34.6) \\ \text { Post } & 144 & 48 \text { (33.3) }\end{array}$

Tumor size at baseline

$\begin{array}{lll}\text { T2 } & 150 & 62(41.3) \\ \text { T3 } & 100 & 28(28.0) \\ \text { T4 } & 53 & 13(24.5)\end{array}$

Node status at baseline

$\begin{array}{lll}- & 52 & 18(34.6) \\ + & 251 & 85(33.9)\end{array}$

Histology at

baseline

$\begin{array}{lll}\begin{array}{l}\text { Invasive ductal } \\ \text { carcinoma }\end{array} & 224 & 82(36.6) \\ \begin{array}{l}\text { Invasive (mixed) } \\ \text { carcinoma }\end{array} & 62 & 17(27.4) \\ \text { Others } & 17 & 4(23.5)\end{array}$

Ki-67 expression at baseline

$\begin{array}{lll}<20 \% & 107 & 22(20.6) \\ \geq 20 \% & 196 & 81(41.3)\end{array}$

sMMP-9 at baseline (ng/ml)

$\begin{array}{lcc}\text { Low }(<505.5) & 101 & 34(33.7) \\ \begin{array}{l}\text { Intermediate } \\ (505.5-712.8)\end{array} & 100 & 38(38.0) \\ \text { High (> 712.8) } & 102 & 31(30.4) \\ \text { sMMP-9 at surgery } \\ \text { (ng/ml) }\end{array}$

Table 1 Patient characteristics and observed pathological complete response ( $\mathrm{pCR}$ ) (Continued)

have definitive value to base therapeutic decisions for TNBC patients. Since current prediction methods using measurements of clinical, pathological and radiological responses lack the necessary precision, the potential utility of serum biomarkers has begun to be investigated

Table 2 Univariate and multivariate survival analysis of non-pCR patients

\begin{tabular}{|c|c|c|c|}
\hline \multirow[t]{3}{*}{ Factors } & \multicolumn{3}{|c|}{ Disease-free survival } \\
\hline & \multirow{2}{*}{$\begin{array}{l}\text { Univariate } \\
\text { P }\end{array}$} & \multicolumn{2}{|c|}{ Multivariate } \\
\hline & & $P$ & HR $(95 \% \mathrm{Cl})$ \\
\hline \multicolumn{4}{|l|}{ Age } \\
\hline$<40$ vs. $40-60$ vs. $\geq 60$ & 0.062 & - & - \\
\hline \multicolumn{4}{|l|}{ Menopausal status } \\
\hline Pre vs. Post & 0.150 & - & - \\
\hline \multicolumn{4}{|l|}{ Initial tumor status } \\
\hline T2 vs. T3 vs. T4 & 0.104 & - & - \\
\hline \multicolumn{4}{|l|}{ Residual tumor size } \\
\hline $\begin{array}{l}\leq 2 \mathrm{~cm} \text { vs. } 2-5 \mathrm{~cm} \\
\text { vs. }>5 \mathrm{~cm}\end{array}$ & $<0.001$ & NS & - \\
\hline \multicolumn{4}{|l|}{ Residual involved nodes } \\
\hline \multirow[t]{3}{*}{0 vs. $1-3$ vs. $\geq 4$} & $<0.001$ & $<0.001$ & 1.000 \\
\hline & & & $1.409(0.604-3.289)$ \\
\hline & & & $4.124(1.948-8.732)$ \\
\hline \multicolumn{4}{|l|}{ Vascular invasion } \\
\hline Negative vs. Positive & 0.035 & NS & - \\
\hline \multicolumn{4}{|l|}{ Grade } \\
\hline | - || vs. ||| & 0.322 & - & - \\
\hline \multicolumn{4}{|l|}{ Ki-67 } \\
\hline$<20 \%$ vs. $\geq 20 \%$ & 0.001 & 0.018 & $1.909(1.117-3.262)$ \\
\hline \multicolumn{4}{|l|}{ sMMP-9 at baseline } \\
\hline Linear & 0.226 & - & \\
\hline \multicolumn{4}{|l|}{ sMMP-9 at surgery } \\
\hline Linear & 0.008 & NS & - \\
\hline \multicolumn{4}{|l|}{ sMMP-9 change } \\
\hline Linear & 0.019 & NS & - \\
\hline \multicolumn{4}{|l|}{ hMMP-9 in residual tumor } \\
\hline \multirow[t]{3}{*}{ - vs. + vs. ++ } & $<0.001$ & 0.004 & 1.000 \\
\hline & & & $2.637(1.341-5.183)$ \\
\hline & & & $2.832(1.348-5.950)$ \\
\hline
\end{tabular}




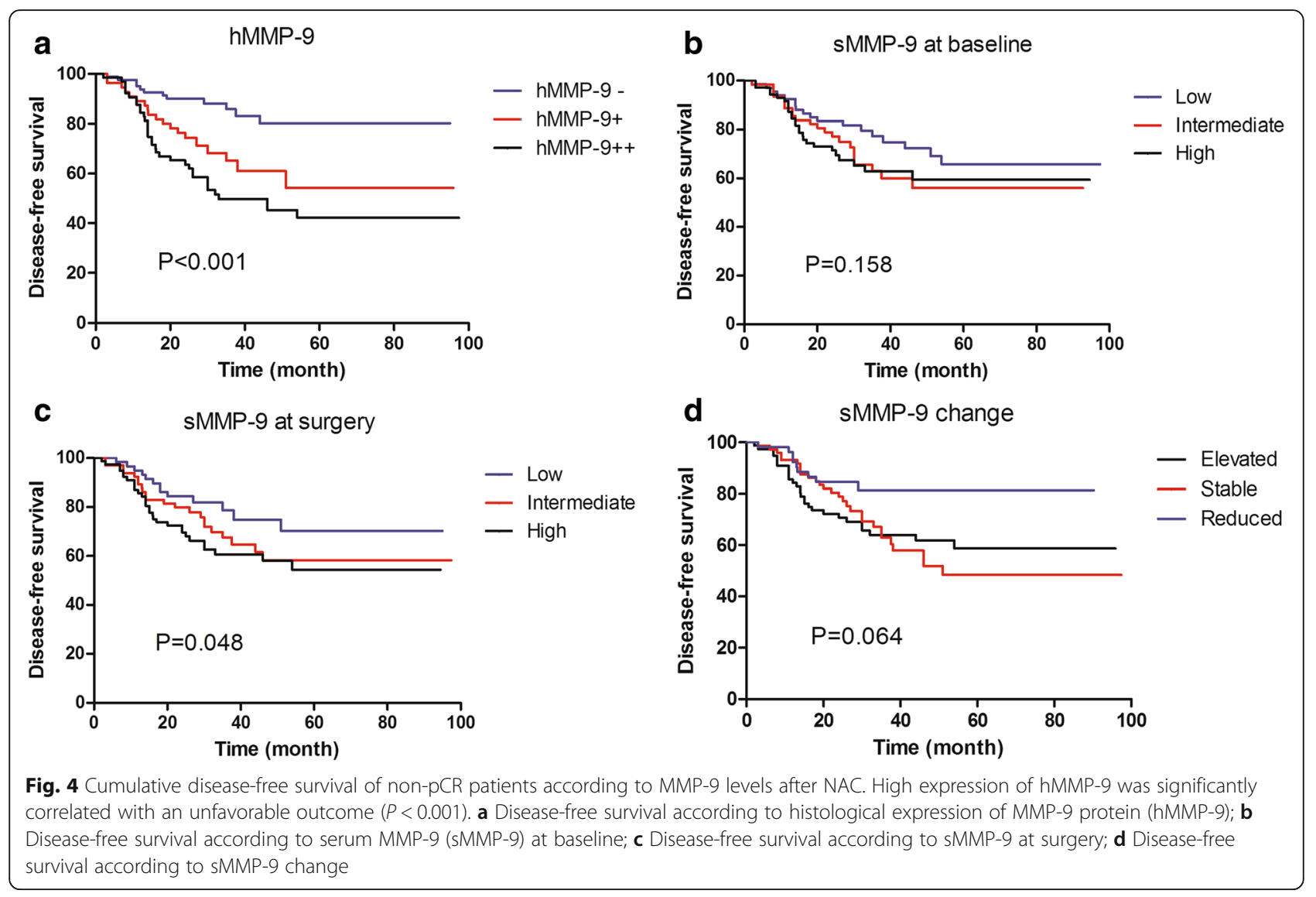

$[16,17]$; however, there is little consensus in the field regarding the predictive and prognostic value of these biomarkers.

MMPs are a large family of proteolytic enzymes of the extracellular matrix and play important roles in extracellular matrix degradation, tumor cell invasion, metastasis and angiogenesis $[8,18,19]$. Among all MMPs, MMP-9 has been the most commonly studied. A recent study stated that GM-CSF and MMP-9 promote the protumorigenic effect of WAT progenitors on local and metastatic breast cancer [20]. Some other study noted that MMP-9 could be regulated by DNA methylation in breast cancer, which might resulted in the first step of metastasis through extracellular matrix degradation [21]. Previously, two meta-analyses published by Song et al., [22] and Ren et al., [12] have verified that MMP-9 overexpression predicted a higher risk for OS and RFS in patients with breast carcinoma; however, few studies have been reported referring the prognostic value of serum MMP-9. Tabouret E et al. reported that low MMP9 serum level was associated with better survival in HER2-positive patients treated with bevacizumab- and trastuzumab-based neoadjuvant chemotherapy [23]. In this study, we also provide evidence that MMP-9 is correlated with survival of patients with breast cancer; however, this is the first study that investigates the prognostic value of MMP-9 in a neoadjuvant setting. Since it is well-known that $\mathrm{pCR}$ responders would achieve a favorable outcome, we mainly focused on the value of MMP-9 in distinguishing non-pCR patients at different levels of recurrence or death risk. Various similar prognostic markers have been described in the literature. Meaningful factors include node status, ER, PgR, and Ki-67 [24-27]. Our study provides another useful biomarker that might help clinicians to discriminate patients with residual tumors into different risk groups for further individualized treatment.

Furthermore, response prediction is extremely important for NAC candidates, especially those with TNBC. If an accurate prediction of response/non-response can be made early in a patient's treatment, the regimen could be modified accordingly; this is known as the responseguided treatment strategy, which may avoid unnecessary treatment-related toxicities and provide a better survival, regardless of pCR [28]. For predicted well-responders, additional NAC cycles with the same regimen are recommended; however, for predicted non-responders, an alternative regimen may be necessary [28]. In the present study, we have demonstrated that serum MMP-9 might correlated to treatment response. The change in MMP-9 
level in serum was independently correlated to the possibility of achieving pCR, with each $1 \mathrm{ng} / \mathrm{ml}$ decrease in the sMMP-9 level after NAC resulting in a $0.3 \%$ increase in the $\mathrm{pCR}$ rate. Our findings also suggest that serum MMP-9 measurement may play a role in the response evaluation at any time point throughout the whole NAC period, considering its decreasing trend in patients with high-chemosensitivity (Fig. 2).

Our findings are mainly based on the serum detection of MMP-9, which may be a safer and more valid method to detect the expression of MMP-9. This approach represents a significant departure from existing models of response monitoring by using imaging-based metrics, also known as clinical response evaluation. Although several studies have indicated that MRI is an effective tool for predicting the response to NAC [29], the accuracy was lower when pCR was more rigorously defined [29] and varies with tumor subtype [30]. More importantly, the clinical response often lacks accuracy in the early prediction of pathologic response to neoadjuvant therapy [31]. Compared to other predictive markers such as Ki-67 [32], monitoring of serum markers such as MMP-9 is relatively convenient and easy to accept by patients. Thus, early detection of a MMP-9 change might be of some value as a complement in response evaluation method of NAC for TNBC. However, more prospective data are needed to further validate its predictive value. A combination of serum biomarkers, histological biomarkers and imaging-based metrics might be the mainstream in the future response evaluation of NAC.

Interestingly, the IHC detection of MMP-9 protein expression shows better prognostic value compared to serum MMP-9 in survival analysis for non-pCR responders, despite a good concordance between SMMP-9 and hMMP-9. It is believed that the residual chemotherapy-resistant disease after NAC is a surrogate for chemotherapy-resistant micrometastatic disease that can ultimately progress into clinically overt metastatic breast cancer. Since TNBCs are initially sensitive to NAC, the residual tumors are generally more aggressive, which results in unfavorable prognoses with short RFS and OS [33, 34]. Furthermore, several reports have suggested that the residual cancer cells in TNBC represent a heterogeneous group comprising subtypes with different outcomes [7]. Therefore, the expression of MMP-9 of residual cancer cells might reflect a subtype of TNBCs with more aggressive behavior, resulting in poor survival.

\section{Conclusion}

We demonstrated a new strategy for response prediction and evaluation for TNBC patients undergoing chemotherapy. The monitoring of serum MMP-9 could help identify patients with favorable responses to NAC, which allows for the modification of NAC regimens. In non-pCR responders, the histological expression of MMP-9 of residual cancer cells is correlated with risk of relapse or death. In future prospective studies, MMP-9 might serve as a complement or alternative to traditional prediction and prognostic evaluating methodologies.

\begin{abstract}
Abbreviations
ELISA: Enzyme-linked immunosorbent assay; ER: Estrogen receptor; HER2: Human epidermal growth factor receptor-2; IHC: Immunohistochemistry; MMP: Matrix metalloproteinase; NAC: Neoadjuvant chemotherapy; PCR: Pathological complete response; PgR: Progesterone receptor; TNBC: Triple-negative breast cancer
\end{abstract}

\section{Acknowledgements}

The authors are grateful to Jiong Wu, Guang-Yu Liu and Zhen-Zhou Shen for their excellent data management.

\section{Funding}

This research was supported by National Natural Science Foundation of China (81302298), Natural Science Foundation of Shanghai (17ZR1405900) and Shanghai Sailing Program (18YF1405000). The funders had no role in the study design, data collection and analysis, decision to publish, or preparation of the manuscript.

Availability of data and materials

The dataset supporting the conclusions of this article is included within the article.

Authors' contributions

WRX and CS contributed to the conception of the study, data analysis and interpretation, and writing the manuscript. WRX and HL made tissue sections and participated in ELISA and immunohistochemical analysis. CS and SZM contributed to the collection and assembly of data. All authors read and approved the final manuscript.

\section{Ethics approval and consent to participate}

Our study was approved by the independent ethical committee/institutional review board of Fudan University Shanghai Cancer Center (Shanghai Cancer Center Ethical Committee). All patients gave their written informed consent before inclusion in this study.

\section{Consent for publication}

NA

\section{Competing interests}

The authors declare that they have no competing interests.

\section{Publisher's Note}

Springer Nature remains neutral with regard to jurisdictional claims in published maps and institutional affiliations.

\section{Author details}

'Department of Breast Surgery, Fudan University Shanghai Cancer Center/ Cancer Institute, 399 Ling-Ling Road, Shanghai 200032, People's Republic of China. ${ }^{2}$ Department of Oncology, Shanghai Medical College, Fudan

University, Shanghai, People's Republic of China. ${ }^{3}$ Institutes of Biomedical Science, Fudan University, Shanghai, People's Republic of China.

Received: 18 January 2018 Accepted: 14 September 2018 Published online: 21 September 2018

References

1. Bauer KR, Brown M, Cress RD, Parise CA, Caggiano V. Descriptive analysis of estrogen receptor (ER)-negative, progesterone receptor (PR)-negative, and HER2-negative invasive breast cancer, the so-called triple-negative phenotype: a population-based study from the California cancer registry. Cancer. 2007; 109(9):1721-8

2. Kong X, Moran MS, Zhang N, Haffty B, Yang Q. Meta-analysis confirms achieving pathological complete response after neoadjuvant chemotherapy predicts favourable prognosis for breast cancer patients. Eur J Cancer. 2011; 47(14):2084-90.

3. Prowell TM, Pazdur R. Pathological complete response and accelerated drug approval in early breast cancer. N Engl J Med. 2012;366(26):2438-41. 
4. von Minckwitz G, Martin M. Neoadjuvant treatments for triple-negative breast cancer (TNBC). Ann Oncol. 2012;23(Suppl 6):vi35-9.

5. Carey LA, Dees EC, Sawyer L, Gatti L, Moore DT, Collichio F, Ollila DW, Sartor $\mathrm{Cl}$, Graham ML, Perou CM. The triple negative paradox: primary tumor chemosensitivity of breast cancer subtypes. Clin Cancer Res. 2007;13(8): 2329-34.

6. Kim T, Han W, Kim MK, Lee JW, Kim J, Ahn SK, Lee HB, Moon HG, Lee KH, Kim TY, et al. Predictive significance of p53, Ki-67, and Bcl-2 expression for pathologic complete response after neoadjuvant chemotherapy for triplenegative breast Cancer. J Breast Cancer. 2015;18(1):16-21.

7. Cheang MC, Voduc D, Bajdik C, Leung S, McKinney S, Chia SK, Perou CM, Nielsen TO. Basal-like breast cancer defined by five biomarkers has superior prognostic value than triple-negative phenotype. Clin Cancer Res. 2008; 14(5):1368-76.

8. Yadav L, Puri N, Rastogi V, Satpute P, Ahmad R, Kaur G. Matrix metalloproteinases and cancer - roles in threat and therapy. Asian Pac J Cancer Prev. 2014;15(3): 1085-91.

9. Cockett MI, Murphy G, Birch ML, O'Connell JP, Crabbe T, Millican AT, Hart IR, Docherty AJ. Matrix metalloproteinases and metastatic cancer. Biochem Soc Symp. 1998;63:295-313.

10. Evans JD, Ghaneh P, Kawesha A, Neoptolemos JP. Role of matrix metalloproteinases and their inhibitors in pancreatic cancer. Digestion. 1997;58(6):520-8.

11. Foda HD, Zucker S. Matrix metalloproteinases in cancer invasion, metastasis and angiogenesis. Drug Discov Today. 2001;6(9):478-82.

12. Ren F, Tang R, Zhang X, Madushi WM, Luo D, Dang Y, Li Z, Wei K, Chen G. Overexpression of MMP family members functions as prognostic biomarker for breast Cancer patients: a systematic review and meta-analysis. PLoS One. 2015;10(8):e0135544

13. Chen XS, Nie XQ, Chen CM, Wu JY, Wu J, Lu JS, Shao ZM, Shen ZZ, Shen KW. Weekly paclitaxel plus carboplatin is an effective nonanthracyclinecontaining regimen as neoadjuvant chemotherapy for breast cancer. Ann Oncol. 2010;21(5):961-7.

14. Eisenhauer EA, Therasse $P$, Bogaerts J, Schwartz LH, Sargent D, Ford R, Dancey J, Arbuck S, Gwyther S, Mooney M, et al. New response evaluation criteria in solid tumours: revised RECIST guideline (version 1.1). Eur J Cancer. 2009:45(2):228-47.

15. Ogston KN, Miller ID, Payne S, Hutcheon AW, Sarkar TK, Smith I, Schofield A, Heys SD. A new histological grading system to assess response of breast cancers to primary chemotherapy: prognostic significance and survival. Breast. 2003;12(5):320-7.

16. Wang $Y$ J, Huang $X Y$, Mo M, Li JW, Jia XQ, Shao ZM, Shen ZZ, Wu J, Liu GY. Serum tumor marker levels might have little significance in evaluating neoadjuvant treatment response in locally advanced breast Cancer. Asian Pac J Cancer Prev. 2015;16(11):4603-8.

17. Nolen BM, Marks JR, Ta'san S, Rand A, Luong TM, Wang Y, Blackwell K, Lokshin AE. Serum biomarker profiles and response to neoadjuvant chemotherapy for locally advanced breast cancer. Breast Cancer Res. 2008;10(3):R45.

18. Westermarck J, Kahari VM. Regulation of matrix metalloproteinase expression in tumor invasion. FASEB J. 1999;13(8):781-92.

19. Alaseem A, Alhazzani K, Dondapati P, Alobid S, Bishayee A, Rathinavelu A. Matrix metalloproteinases: a challenging paradigm of cancer management. Semin Cancer Biol. 2017;(17)30184-0. https://doi.org/10.1016/j.semcancer. 2017.11.008.

20. Reggiani F, Labanca V, Mancuso P, Rabascio C, Talarico G, Orecchioni S, Manconi A, Bertolini F. Adipose progenitor cell secretion of GM-CSF and MMP9 promotes a stromal and immunological microenvironment that supports breast Cancer progression. Cancer Res. 2017;77(18):5169-82.

21. Klassen LMB, Chequin A, Manica GCM, Biembengut IV, Toledo MB, Baura VA, de OPF REAS, Costa FF, de Souza EM, et al. MMP9 gene expression regulation by intragenic epigenetic modifications in breast cancer. Gene. 2018; 642:461-6.

22. Song J, Su H, Zhou YY, Guo LL. Prognostic value of matrix metalloproteinase 9 expression in breast cancer patients: a meta-analysis. Asian Pac J Cancer Prev. 2013;14(3):1615-21.

23. Tabouret E, Bertucci F, Pierga JY, Petit T, Levy C, Ferrero JM, Campone M,

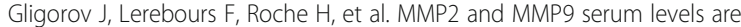
associated with favorable outcome in patients with inflammatory breast cancer treated with bevacizumab-based neoadjuvant chemotherapy in the BEVERLY-2 study. Oncotarget. 2016;7(14):18531-40.
24. Rouzier R, Pusztai L, Delaloge S, Gonzalez-Angulo AM, Andre F, Hess KR, Buzdar AU, Garbay JR, Spielmann M, Mathieu MC, et al. Nomograms to predict pathologic complete response and metastasis-free survival after preoperative chemotherapy for breast cancer. J Clin Oncol. 2005;23(33): 8331-9.

25. Guarneri V, Piacentini F, Ficarra G, Frassoldati A, D'Amico R, Giovannelli S, Maiorana A, Jovic G, Conte P. A prognostic model based on nodal status and $\mathrm{Ki}-67$ predicts the risk of recurrence and death in breast cancer patients with residual disease after preoperative chemotherapy. Ann Oncol. 2009; 20(7):1193-8.

26. Symmans WF, Peintinger F, Hatzis C, Rajan R, Kuerer H, Valero V, Assad L, Poniecka A, Hennessy B, Green M, et al. Measurement of residual breast cancer burden to predict survival after neoadjuvant chemotherapy. J Clin Oncol. 2007;25(28):4414-22.

27. Colleoni M, Bagnardi V, Rotmensz N, Dellapasqua S, Viale G, Pruneri G, Veronesi P, Torrisi R, Luini A, Intra M, et al. A risk score to predict disease-free survival in patients not achieving a pathological complete remission after preoperative chemotherapy for breast cancer. Ann Oncol. 2009;20(7):1178-84.

28. von Minckwitz G, Kummel S, Vogel P, Hanusch C, Eidtmann H, Hilfrich J, Gerber B, Huober J, Costa SD, Jackisch C, et al. Neoadjuvant vinorelbinecapecitabine versus docetaxel-doxorubicin-cyclophosphamide in early nonresponsive breast cancer: phase III randomized GeparTrio trial. J Natl Cancer Inst. 2008;100(8):542-51

29. Marinovich ML, Houssami N, Macaskill P, Sardanelli F, Irwig L, Mamounas EP, von Minckwitz G, Brennan ME, Ciatto S. Meta-analysis of magnetic resonance imaging in detecting residual breast cancer after neoadjuvant therapy. J Natl Cancer Inst. 2013;105(5):321-33.

30. McGuire KP, Toro-Burguete J, Dang H, Young J, Soran A, Zuley M, Bhargava R, Bonaventura M, Johnson R, Ahrendt G. MRI staging after neoadjuvant chemotherapy for breast cancer: does tumor biology affect accuracy? Ann Surg Oncol. 2011;18(11):3149-54

31. Marinovich ML, Sardanelli F, Ciatto S, Mamounas E, Brennan M, Macaskill P, Irwig L, von Minckwitz G, Houssami N. Early prediction of pathologic response to neoadjuvant therapy in breast cancer: systematic review of the accuracy of MRI. Breast. 2012;21(5):669-77.

32. Denkert $C$, Loibl S, Muller BM, Eidtmann H, Schmitt WD, Eiermann W, Gerber B, Tesch H, Hilfrich J, Huober J, et al. Ki67 levels as predictive and prognostic parameters in pretherapeutic breast cancer core biopsies: a translational investigation in the neoadjuvant GeparTrio trial. Ann Oncol. 2013;24(11): 2786-93.

33. Nahleh Z. Neoadjuvant chemotherapy for "triple negative" breast cancer: a review of current practice and future outlook. Med Oncol. 2010;27(2):531-9.

34. Keam B, Im SA, Lee KH, Han SW, Oh DY, Kim JH, Lee SH, Han W, Kim DW, Kim TY, et al. Ki-67 can be used for further classification of triple negative breast cancer into two subtypes with different response and prognosis. Breast Cancer Res. 2011;13(2):R22

Ready to submit your research? Choose BMC and benefit from

- fast, convenient online submission

- thorough peer review by experienced researchers in your field

- rapid publication on acceptance

- support for research data, including large and complex data types

- gold Open Access which fosters wider collaboration and increased citations

- maximum visibility for your research: over $100 \mathrm{M}$ website views per year

At $\mathrm{BMC}$, research is always in progress.

Learn more biomedcentral.com/submissions 